\title{
Structure and Magnetic Properties of the Radical Cation Salt of a TTF-based Ni ${ }^{\text {il }}$ Complex
}

\author{
S-X. Liu ${ }^{a}$, C. Ambrus ${ }^{a}$, S. Dolder ${ }^{a}$, A. Neels ${ }^{b}$, G. Labat ${ }^{b}$, and \\ S. Decurtins ${ }^{\mathrm{a}, *}$
}

${ }^{a}$ Departement für Chemie und Biochemie, Universität Bern, Freiestrasse 3, CH-3012 Bern, Switzerland

${ }^{b}$ Institut de Chimie, Université de Neuchâtel, Avenue de Bellevaux 51, CH2007 Neuchâtel, Switzerland

Chemical oxidation of a TTF-based $\mathrm{Ni}^{\text {II }}$ complex with $\mathrm{I}_{2}$ produces the corresponding radical cation salt $1,\left[\mathrm{Ni}_{2} \mathrm{Cl}_{2}(\mathrm{~L})_{2}\right]\left(\mathrm{I}_{3}\right)_{2}\left(\mathrm{I}_{5}\right)_{2}\left(\mathrm{I}_{2}\right)\left(\mathrm{H}_{2} \mathrm{O}\right)_{2}\left(\mathrm{C}_{4} \mathrm{H}_{8} \mathrm{O}\right)_{3}$, ( $L=4,5$-bis(2-pyridylmethylsulfanyl)-4',5'-ethylenedithiotetrathiafulvalene).

The results of magnetic susceptibility measurements show the occurrence of intramolecular magnetic exchange interactions in 1. The lack of close $S \cdots S$ contacts, confirmed by crystal structure analysis, results in an insulating behavior.

PACS numbers: $81.05 t, 81.10 \mathrm{Dn}, 61.10 \mathrm{Nz}$.

\section{INTRODUCTION}

One of the current objectives in the field of conducting molecular materials derived from tetrathiafulvalene (TTF) is to try to correlate within the same solid two distinct physical properties such as magnetic and conducting properties, seeking to establish in this case a coupling between the conduction electrons and the magnetic spin moments ${ }^{1,2}$. Numerous research groups are involved in this area $^{3}$. In addition to co-assembling organic donors and paramagnetic metal anions, another strategy for constructing dual-property materials is the direct coordination of paramagnetic metal ions to organic radicals through an intervening coordination function such as pyridine-type heterocycles ${ }^{4}$ or phosphine substituents ${ }^{5}$, both well-known for their chelating ability toward various transition metal complexes. Although a large number of inorganic/organic hybrid materials contain metal ions in an anionic part, only a few examples of the direct coordination of the paramagnetic metal ions to TTF derivatives have been reported ${ }^{6,7}$. It is noteworthy that the coordination of metal ions to TTF derivatives might constitute an approach for the achievement of $\pi$-d interactions in such multifunctional molecular materials. As a result, we 
report here on the synthesis, characterization, and properties of the radical cation salt of a $\mathrm{Ni}^{\mathrm{iI}}$ chloride complex of 4,5-bis(2-pyridylmethylsulfanyl)4',5'-ethylenedithiotetrathiafulvalene (L).

\section{EXPERIMENTAL PART}

$10 \mathrm{ml}$ of a $10 \mathrm{mM}$ clear solution of $\mathrm{I}_{2}$ in $\mathrm{CH}_{2} \mathrm{Cl}_{2}$ was introduced into a glass tube and layered successively with $4 \mathrm{ml}$ pure $\mathrm{CH}_{2} \mathrm{Cl}_{2}$ and $4 \mathrm{ml}$ of pure THF as a buffer zone. Then $10 \mathrm{ml}$ of a $1.2 \mathrm{mM}$ solution of $\mathrm{Ni}(\mathbf{L}) \mathrm{Cl}_{2}^{7}$ in $\mathrm{CH}_{2} \mathrm{Cl}_{2}$ was added very gently to avoid possible mixing. The glass tube was sealed and left in the dark at room temperature for four days. Black single crystals were isolated at the interface between the two solutions. Anal. Calc. for $\mathrm{C}_{40} \mathrm{H}_{32} \mathrm{~N}_{4} \mathrm{~S}_{16} \mathrm{Ni}_{2} \mathrm{Cl}_{4}\left(\mathrm{I}_{3}\right)_{2}\left(\mathrm{I}_{5}\right)_{2}\left(\mathrm{I}_{2}\right) \cdot \mathrm{C}_{4} \mathrm{H}_{8} \mathrm{O} \cdot 2 \mathrm{H}_{2} \mathrm{O}: \mathrm{C}, 14.43 ; \mathrm{H}, 1.21 ; \mathrm{N}, 1.53$. Found: C, 14.52; H, 0.92; N, 1.42. IR (KBr, cm $\left.{ }^{-1}\right)$ : 3431, 1668, 1661, 1568, $1481,1439,1385,1268,1156,1057,1019$.

\section{RESULTS AND DISCUSSION}

Based on the neutral $\mathrm{Ni}(\mathbf{L}) \mathrm{Cl}_{2}$ compound $^{7}$, we aimed to obtain corresponding TTF radical cation salts by electrocrystallization with a range of suitable anions as well as by chemical oxidation. Consequently, chemical oxidation with $\mathrm{I}_{2}$ by slow layer diffusion produces the crystalline dimeric $\mathrm{Ni}^{\mathrm{II}}$ compound $\mathbf{1}$, as shown in Figure 1, formulated as $\left[\mathrm{Ni}_{2} \mathrm{Cl}_{2}(\mathrm{~L})_{2}\right]\left(\mathrm{I}_{3}\right)_{2}\left(\mathrm{I}_{5}\right)_{2}\left(\mathrm{I}_{2}\right)\left(\mathrm{H}_{2} \mathrm{O}\right)_{2}\left(\mathrm{C}_{4} \mathrm{H}_{8} \mathrm{O}\right)_{3}$. Crystal structure analysis (monoclinic, $\mathrm{C} 2 / \mathrm{c}$ ) reveals that the bond lengths around the $\mathrm{Ni}$ atom in $\mathbf{1}$ are very close to those found in the neutral complex $\mathrm{Ni}(\mathbf{L}) \mathrm{Cl}_{2}$.

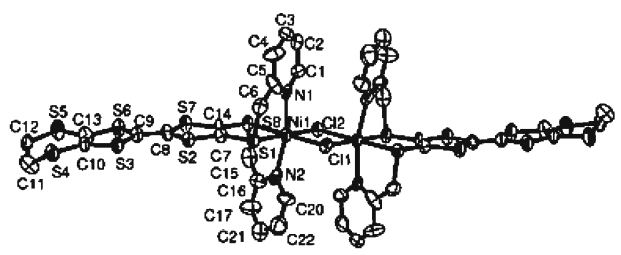

Fig. 1. ORTEP plot (50\% probability ellipsoids) showing the $\mathrm{Ni}^{\mathrm{II}}$ coordination sphere of $\mathbf{1}$. Anions, solvents and hydrogen atoms are omitted for clarity. The two halfs of the molecule are related by an inversion center.

The ionicity of the donor $\mathbf{L}$ can be estimated from the $\mathrm{C}=\mathrm{C}$ bond length [1.41(3) $\AA$ in 1] of the TTF unit, being slightly larger than in the neutral complex [1.334(8) $\AA$ ]. Thus, it can be inferred that the TTF core in $\mathbf{1}$ is essentially fully oxidized according to the correlation between the oxidation 
states of TTF derivatives and bond lengths of central $\mathrm{C}=\mathrm{C}$ bonds ${ }^{8}$. In order to get further experimental information about the electronic distribution within the donor moieties, we have performed Raman microscope measurements on single crystals of $\mathbf{1}$. From the linear relationship found in other TTF salts ${ }^{9}$ between the the $\mathrm{C}=\mathrm{C}$ stretching frequencies $v_{2}, v_{3}$ and the degree of ionicity $(\rho)$, one can estimate $\rho$ for the two $\mathbf{L}$ moieties in compound 1. Thus, if the two doublets centered at 1467 and $1422 \mathrm{~cm}^{-1}$ are assigned to $v_{2}$ and $v_{3}$ modes, respectively, one can estimate by interpolation a $\rho$ value of 1 . These results are also consistent with the stoichiometry of 1 and the fact that the oxidized compound $\mathbf{1}$ is black in color, while its neutral complex is brown. However, due to a bulky coordination sphere, there are no close S $\cdots$ S contacts observed in this oxidized ionic salt (Figure 2), which results in an insulating behavior.

Magnetic susceptibility measurements of 1 (Figure 3) reveal, as expected, the occurrence of intramolecular magnetic exchange interactions. Essentially, there is a ferromagnetic coupling between the $\mathrm{Ni}^{\mathrm{II}}$ spins $(S=1)$ mediated through the $\mu$-dichloro bridge and a weaker antiferromagnetic coupling to the pendant radical sites. Of course, zero-field splitting for the $\mathrm{Ni}^{\mathrm{II}}$ ions will be significant at lower temperatures, too.

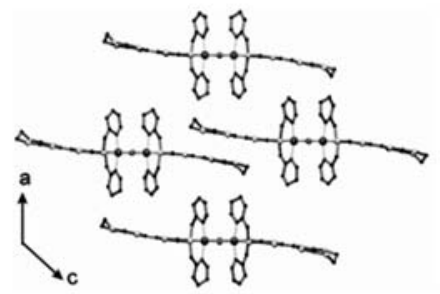

Fig. 2. $a c$ projection of the crystal structure of 1 . Anions, solvents and hydrogen atoms are omitted for clarity.

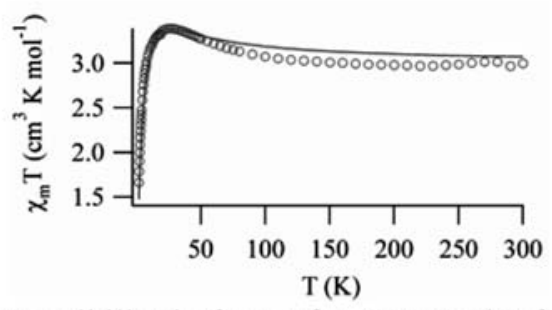

Fig. 3. Magnetic susceptibility in form of $\chi_{\mathrm{m}} \mathrm{T} v s \mathrm{~T}$ plot for compound $\mathbf{1}$. The solid line shows a simulation of the intramolecular magnetic interactions. 


\section{CONCLUSIONS}

A new radical cation salt of a TTF-based $\mathrm{Ni}^{\mathrm{II}}$ complex, $\mathbf{1}$, has been prepared by chemical oxidation with $\mathrm{I}_{2}$, and also structurally characterized. The preliminary results of magnetic susceptibility measurements show the occurrence of intramolecular magnetic exchange interactions in 1. A full paper about these results will be ready for publication in due course.

\section{ACKNOWLEDGEMENTS}

We would like to thank the SNF for financial support.

\section{REFERENCES}

1. E. Coronado, J. R. Galán-Mascarós, C. J. Gómez-García and V. Laukhin, Nature 408, 447 (2000); H. Kobayashi, H-B. Cui and A. Kobayashi, Chem. Rev.104, 5419 (2004); A. Kobayashi, E. Fujiwara and H. Kobayashi; Chem. Rev.104, 5243 (2004).

2. L. Ouahab and T. Enoki, Eur. J. Inorg. Chem. 933 (2004); E. Coronado and P. Day, Chem. Rev.104, 5265 (2004).

3. H. Kobayashi, A. Kobayashi and P. Cassoux, Chem. Soc. Rev. 29, 325 (2000); T. Enoki and A. Miyazaki, Chem. Rev.104, 5449 (2004).

4. S. Bouguessa, A. K. Gouasmia, S. Golhen, L. Ouahab and J. M. Fabre, Tetrahedron Lett. 44, 9275 (2003); S-X. Liu, S. Dolder, E. B. Rusanov, H. Stoeckli-Evans and S. Decurtins, C. R. Acad. Sci. Paris, Chimie 6, 657 (2003); S-X. Liu, S. Dolder, M. Pilkington and S. Decurtins, J. Org. Chem. 67, 3160 (2002).

5. T. Devic, P. Batail, M. Fourmigue and N. Avarvari, Inorg. Chem. 43, 3136 (2004); P. Pellon, G. Gachot, J. Le Bris, S. Marchin, R. Carlier and D. Lorcy, Inorg. Chem. 42, 2056 (2003).

6. F. Setifi, L. Ouahab, S. Golhen, Y. Yoshida and G. Saito, Inorg. Chem. 42, 1791 (2003).

7. S-X. Liu, S. Dolder, P. Franz, A. Neels, H. Stoeckli-Evans and S. Decurtins, Inorg. Chem. 42, 4801 (2003).

8. M. B. Inoue, M. Inoue, M. A. Bruck and Q. Fernando, J. Chem. Soc., Chem. Commun. 515 (1992).

9. K. Yamamoto and K. Yakushi, Phys. Rev. B. 65, 085110 (2002). 